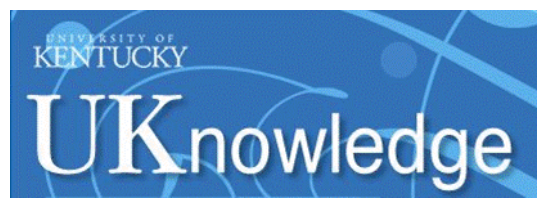

University of Kentucky

UKnowledge

9-2015

\title{
Intrapersonal Competencies and Service Leadership
}

Daniel T. L. Shek

University of Kentucky

Li Lin

Hong Kong Polytechnic University, China

Follow this and additional works at: https://uknowledge.uky.edu/pediatrics_facpub

Part of the Pediatrics Commons

Right click to open a feedback form in a new tab to let us know how this document benefits you.

\section{Repository Citation}

Shek, Daniel T. L. and Lin, Li, "Intrapersonal Competencies and Service Leadership" (2015). Pediatrics Faculty Publications. 213.

https://uknowledge.uky.edu/pediatrics_facpub/213

This Article is brought to you for free and open access by the Pediatrics at UKnowledge. It has been accepted for inclusion in Pediatrics Faculty Publications by an authorized administrator of UKnowledge. For more information, please contact UKnowledge@lsv.uky.edu. 


\section{Intrapersonal Competencies and Service Leadership}

\section{Digital Object Identifier (DOI)}

https://doi.org/10.1515/ijdhd-2015-0406

\section{Notes/Citation Information}

Published in International Journal on Disability and Human Development, v. 14, no. 3, p. 255-263.

(c) 2015 Walter de Gruyter GmbH, Berlin/Boston

The copyright holders have granted the permission for posting the article here. 


\section{Daniel T.L. Shek* and Li Lin \\ Intrapersonal competencies and service leadership}

DOI 10.1515/ijdhd-2015-0406

Received April 10, 2014; accepted June 10, 2014; previously published online August 27, 2015

\begin{abstract}
Intrapersonal competencies form the foundation of one's development, and they are fundamental qualities of leadership competences. Four types of intelligence are highlighted in the literature of positive psychology: intelligence quotient (IQ), emotional intelligence quotient (EQ), adversity quotient (AQ) and spiritual intelligence quotient (SQ). It is argued that these competences are important in a service leader. Through this lecture, it is expected that students will understand the basic concepts and the importance of different intrapersonal competencies (IQ, $\mathrm{EQ}, \mathrm{AQ}$ and SQ). We also discuss the relationship between these intrapersonal competencies and effective service leadership. Finally, ways to promote different intrapersonal competencies are depicted.
\end{abstract}

Keywords: adversity; emotional intelligence; intelligence; resilience; spirituality.

\section{Introduction}

What does a competent service leader look like? The common answer is "high intrapersonal intelligence is one of the characteristics". According to Gardner's multiple intelligence theory [1], intrapersonal intelligence

*Corresponding author: Daniel T.L. Shek, PhD, FHKPS, BBS, SBS, JP, Chair Professor of Applied Social Sciences, Faculty of Health and Social Sciences, Department of Applied Social Sciences, The Hong Kong Polytechnic University, Room HJ407, Core H, Hunghom, Hong Kong, P.R. China, E-mail: daniel.shek@polyu.edu.hk; Center for Innovative Programs for Adolescents and Families, The Hong Kong Polytechnic University, Hong Kong, P.R. China; Department of Social Work, East China Normal University, Shanghai, P.R. China; Kiang Wu Nursing College of Macau, Macau, P.R. China; Hong Kong Institute of Service Leadership and Management, Hong Kong, P.R. China; and Division of Adolescent Medicine, Department of Pediatrics, Kentucky Children's Hospital, University of Kentucky College of Medicine, Lexington, KY, USA

Li Lin: Department of Applied Social Sciences,

The Hong Kong Polytechnic University, Hong Kong, P.R. China refers to "the effective working model of oneself and the ability to use the model effectively in light of your desires, needs, wishes, fears, and skills" [2, p. 29]. Intrapersonal intelligence and its related competencies are perceived as assets to a leader. For example, Hogan and Kaiser [3] identified four kinds of managerial competence: intrapersonal skills, interpersonal skills, business skills and leadership skills. In his conceptualization, intrapersonal skills refer to "internalized standards of performance" and the ability to "control emotions and behavior" (p. 173). Similarly, Day [4] considered intrapersonal competencies to be the fundamental qualities of leader development, and they were conceptualized in terms of self-awareness, self-regulation and self-motivation. Generally speaking, intrapersonal competencies process information about the self and involve a wide range of abilities related to selfunderstanding and self-management.

This lecture on the subject "Service Leadership" focuses on four kinds of intelligence underlying intrapersonal competencies dealing with problem-solving, emotion management, adversity resilience and the meaning of life. They are termed intelligence quotient (IQ), emotional intelligence quotient (EQ), adversity quotient (AQ) and spiritual intelligence quotient (SQ). All four kinds of intelligence are regarded as relevant to service leadership and thus deserve more in-depth discussion.

\section{Intrapersonal competencies}

IQ pertains to a score derived from standardized intelligence tests such as the Wechsler tests or Raven's Progressive Matrices. Though based on different intelligence theories, these intelligence tests generally assess cognitive abilities of human beings, e.g. memory, verbal ability, arithmetic ability, logic reasoning and visual-spatial perception. A standardized score is generated by referring to a normed sample. In other words, IQ indicates the relative position of an individual's intelligence in a given population.

IQ is important because of its well-documented association with academic and career achievement, though to what extent is debatable. Summarizing prior research, Neisser et al. [5] found that IQ explained about 30\% 
of the variance of years of schooling, $25 \%$ of the social status variance and one-sixth of the income variance. Moreover, according to Sternberg et al. [6], IQ accounted for $4 \%-30 \%$ of job performance variance. IQ was associated with leadership performance as well. In Simonton's [7] study of the previous 44 US presidents before George Bush, IQ scores predicted the ratings of leadership performance. Admittedly, strong cognitive ability is a leader's advantage because leadership is a complex process requiring high-level information processing, problem solving, environment monitoring and creativity [8-10]. Nevertheless, a comprehensive meta-analysis [8] showed that the association of intelligence and leadership effectiveness (perceived effectiveness: $r=0.17$; objective effectiveness: $r=0.33$ ) was not as strong as expected. Recent researchers pay more attention to the non-intellectual aspects of intelligence in leadership processes, such as emotional intelligence [11], adversity quotient (AQ) [12] and spiritual intelligence [13]. These "non-intellectual" competencies are important because effective leaders are excellent at motivating others, conquering adversity and sharing vision and value, which requires much more than cognitive ability.

Notwithstanding the predictive value of IQ to academic performance and job performance, many non-intellectual factors contribute to the success of life and career. EQ is one of the factors related to our thriving. Salovey and Mayer [14] proposed the concept of EQ as a distinct intelligence, which was regarded as relevant to life success. Initially, they defined EQ as “the ability to monitor one's own and others' feelings and emotions, to discriminate among them and to use this information to guide one's thinking and actions" [14, p. 189]. Mayer et al. [15] found that EQ was associated with individual and social life in many domains such as school, delinquent behavior, prosocial behavior, leader-follower relationship, and customer relationship. Goleman [11, 16-18] highly advocated this idea with a broader conceptualization. In particular, he focused on how EQ is translated into career success by arguing that EQ integrates a wide range of emotion-related attitudes, knowledge, abilities and skills, distinguishes the outstanding staff from the average. According to Golemen's view [18], three types of competencies are needed for a given position: technical skills, e.g. MS Office applications; cognitive abilities, such as logical reasoning; and abilities related to emotion, e.g. handling one's frustration. Technical skills and pure cognitive ability merely indicate the threshold competencies to obtain and maintain a job in a given profession, which is far from adequate for being an excellent performer, let alone being an outstanding leader. In contrast, EQ contains both cognitive and emotional skills that help people deal with the emotions of self and others, which further enhances great work performance and leadership.

Under this main assertion, Goleman [11] proposed a model of EQ in terms of a theory of performance. This model is very influential and has inspired much research regarding EQ in the workplace. Goleman [11] divided EQ into five domains: self-awareness, self-regulation, motivation, empathy and social skills. Self-awareness helps leaders to identify and understand the emotions of oneself and its impact on others. Self-regulation enables leaders to control impulsive and detrimental emotions and to behave rationally. Intrinsic motivation helps leaders to be energetic and persistent in their work. Empathy enables leaders to understand others' perspectives and feel their affective state. All four mentioned domains contribute to social skills in building and sustaining social relationships, which further facilitate the attainment of leadership.

Inspired by Goleman's work, a great deal of empirical research has been conducted to demonstrate the association between EQ and leadership effectiveness. For example, based on a sample of 98 senior managers in the public sector, Carmeli [19] found that EQ was positively associated with positive work attitudes, altruistic behavior and work performance. Rosete and Ciarrochi [20] discovered that EQ, assessed by the scale MSCEIT (Mayer, Salovey, Caruso Emotional Intelligence Test) [21], predicted leadership effectiveness beyond the effect of cognitive intelligence and personality among senior managers. The last example was a study conducted by Kerr et al. [22] based on 1258 employee ratings of 38 supervisors' leadership performance. They found that supervisors with high scores in "identifying emotions" and "using emotions to enhance reasoning" were regarded as more effective in a supervisory role.

Despite the varied definitions of $\mathrm{EQ}$, researchers and practitioners mostly believe that leadership is a highly emotion-laden process, and hence leaders should be able to manage their own emotions and influence their followers' emotions. Walter et al. [23] suggest taking EQ into account in leader selection and promotion. Meanwhile, some researchers believe that EQ can be learned [18]. Thus, a related curriculum is highly desirable to nurture service leaders.

While EQ addresses a batch of competencies dealing with emotional issues regardless of the nature of emotion, AQ specifically addresses issues of failure, misfortune or other kinds of severe adversity. Stoltz and Christensen [12] proposed the concept of "adversity quotient" in their book Adversity Quotient: Turning Obstacles into Opportunities. Accordingly, AQ "is the precise, measurable, unconscious 
pattern of how you respond to adversity" [12, p. 23]. The authors state that how well one withstands adversity and overcomes difficulties indicates how much one can achieve.

$\mathrm{AQ}$ is closely related to resilience. Resilience is defined as a "dynamic process encompassing positive adaptation within the context of significant adversity" [24, p. 543] or a characteristic of an individual who can "respond quickly and constructively to crises" [25, p. 3]. The concept of resilience has elicited much heated scientific discussion, especially in the positive psychology movement $[26,27]$. In the beginning, research on resilience mainly focused on the development of children and adolescents who were raised in high-risk situations, e.g. poverty, parental problems, chronic illness [28-30], or suffered a traumatic experience, e.g. maltreatment [31, 32]. It is surprising to note that in a similar adverse situation, some children did not have salient psychosocial problems. For example, when interviewing 330 adolescents who had been Ugandan child soldiers, Klasen et al. [33] found that $27.6 \%$ of them did not show posttraumatic stress disorder, depression or other behavioral and emotional problems at the psychopathological level. Individual differences in having "protective factors", including resources or competencies within the individual, the family, peers, the school or community may yield different levels of resilience to adversity [34]. Identifying the protective factors and examining the underlying mechanisms soon became the major work of proponents of resilience to developmental adversity.

Stoltz and Christensen [12] extended the idea of resilience to the business realm, but treated it as an individual capacity to withstand and bounce back from adversity. In line with other scholars and practitioners [35-37], Stoltz [38] called for fostering resilience as a significant quality of leadership in the business realm. It is inevitable for a leader to encounter a variety of failure, misfortune or loss in his/her career, and it is usually accompanied by negative emotions such as disappointment, confusion, anger, guilt or shame. How to manage setbacks is vital to leadership quality. Resilience is not equal to toughness. Toughness is about suppressing emotion in the face of negative consequences, whereas resilience reflects not only accepting misfortune or failure but also rebounding stronger than before [36]. The leader's resilience not only benefits the leader, but also positively influences others. For example, resilient leaders may serve as role models for others, who then further build the foundation of resilience at the organizational level [38].

In summary, despite the sparse empirical studies done on resilience in the leadership field, people commonly believe in the importance of improving resilience among leaders. The ability to successfully cope with adversity and bounce back in face of hardship can be trained [36, 38]. It is necessary to deliver knowledge and skills of resilience-related competence to students in the service leadership subject.

In addition to IQ, EQ and $\mathrm{AQ}$, there is a growing literature on the importance of spirituality. King and Rothstein [35] regarded belief system as a protective factor that contributes to the resilience process. The belief system includes meanings, goals and fundamental values, which serve as a guide to carry people through adversity. The authors highlighted the importance of spirituality in human life. Spirituality as an intelligence was proposed by Danah Zohar and associates [13]. Later, increasing efforts were put toward uncovering the nature and function of spiritual intelligence in human life. Despite a lack of consensus on the definition of spiritual intelligence, most researchers $[13,39,40]$ regard spiritual intelligence as an ability to deal with meanings, purposes, values and other spiritual resources and use them to solve problems. To illustrate, Zohar [41] saw spiritual intelligence as an intelligence that causes someone to "wrestle with questions of meaning and value" and that impels someone to engage in his/her life with "some kind of service to some higher or deeper cause” (p. 62). In addition, Emmons [40] viewed spiritual intelligence as "the adaptive use of spiritual information to facilitate everyday problem solving and goal attainment” (p. 59).

It is controversial to consider spirituality as an intelligence. Spirituality pertains to meaning and purpose in life, attitudes and responses toward death and dying, the search for the sacred or infinite including religion, hope and despair, forgiveness and restoration of health [42]. It appears irrelevant to the intelligence that traditionally deals with a wide range of cognitive abilities for adaption. However, Emmons [39, 40] pointed out the overlapping conceptual framework of spirituality and intelligence as a problem-solving talent $[43,44]$ by arguing that spiritual resources can be exploited to adaptively solve problems in life. Prior literature supports this idea by stating that spiritual resources can be utilized to improve intrapersonal growth and leadership effectiveness.

Spiritual intelligence can be manifested in a clear meaning of life or purpose in life. The discussion of life meaning is rooted in the eudaemonic theories of wellbeing, which emphasize personal growth over pleasure in the conceptualization of well-being [45]. According to Frankl's premise of "will to meaning" [46], humans have an innate drive to search for meaning and purpose in their lives, and the lack of meaning may lead to maladaptive functioning. This notion has been evident in burgeoning 
research. Zika and Chamberlain's [47] study of a mother sample and an elderly sample showed that meaning in life was found to be positively associated with well-being, e.g. positive affect and emotional ties, and negatively associated with ill-being, e.g. depression, anxiety and loss of control. Particularly in young people, the role of spirituality is also profound. Shek's [48, 49] early works assessing Hong Kong secondary school and university students' purposes in life revealed that spirituality was positively associated with well-being and negatively associated with general psychological problems and hopelessness. Recently, based on 1807 Hong Kong adolescents, Ho et al. [50] found that meaning of life predicted heightened life satisfaction in different life domains (i.e. a latent factor including life satisfaction of family, friends, health, school life and self), and less psychosocial problems (i.e. a latent factor including anxiety, depression, alienation and social maladjustment) through bolstering optimism (against pessimism).

The benefits of spirituality extend to the workplace. Laabs [51] believed "something spiritual is creeping into the workplace, and it seems to be gearing up to be more than a trend" [p. 60]. A successful leader is apt to inspire people and instill in them a vision to strive for [41]. When people recognize the meaning of their work and foresee their future mission, they will engage and persist in their current duties. This notion has been adopted in many ideologies of leadership. Spiritual leadership that emphasizes communicating vision and developing a sense of membership in employees would most probably be the theory that comes to mind [52]. Other models such as servant leadership, transformational leadership, authentic leadership and charismatic leadership also treat spiritual intelligence as a quality leading to effective leadership. For example, charismatic leadership emphasizes the ability to develop and articulate an inspirational vision, so that followers will devote themselves to their collective mission [53]. Transformational leadership and servant leadership share the importance of vision in motivating followers [54, 55]. In addition, authentic leadership advocates a rediscovery of spirit within the self and a connection with others with shared meaning [56].

Leaders who are able to promote the spirituality of employees can contribute to the development of an organization. By summarizing a body of literature on spirituality at work, Karakas [57] believed that spirituality can foster the employees' well-being, meaningfulness of the job and a sense of interconnectedness. These all promote organizational performance such as productivity. In view of a business world with excessive material concerns, Zohar [41] called for adding a moral element to business, making it more service- and value-oriented. To this end, a service leader who knows how to develop a collective vision and inspire followers to transcend physical pursuits or self-interest is highly recommended.

\section{Intrapersonal competencies and service leadership}

According to the SLAM framework [58], Service leadership is "about promoting and inspiring competitive advantage by the use of smartness, EQ, SQ, and inspiration rather than by only smartness and hard power". As a service leader, a certain level of smartness such as problemsolving skills is needed to develop and deliver high quality service. During the service delivery process, uncertainty, misunderstanding, failure, loss or unexpected changes are inevitable. Serving the needs of others and systems demands transcending self-interest. Therefore, the ability to handle emotions of self and others, to conquer adversity and to transcend physical pursuit needs to be improved as well. To nurture holistic development of university students, we designed a lecture to discuss the four facets of intrapersonal competencies (IQ, EQ, AQ and SQ). We encourage students to reflect on their current intrapersonal competencies and seek ways to improve them.

\section{Lecture content}

Intrapersonal competencies mean a person's ability to "recognize one's own unique way of perceiving and comprehending the world" [59]. Because the competencies form the foundation of one's development and behavior, they are essential to leadership competencies. Intrapersonal competencies involve a variety of intelligences related to problem-solving, emotion management, adversity resilience and meaning of life, which are conceptualized as IQ, EQ, AQ and SQ. These intelligences are important for a person to recognize correctly and respond rationally to various environment challenges. In this lecture, intrapersonal competencies of service leadership as well as ways of self-promotion will be introduced to students, so that they will gain not only theoretical knowledge, but also the awareness to their own internal intelligence.

It is expected that after taking this lecture, the students will be able to: a) understand the basic concept of different intrapersonal competencies (IQ, EQ, AQ and $\mathrm{SQ})$; b) understand the importance of developing 
Table 1: Lecture plan.

\begin{tabular}{ll}
\hline & Teaching content \\
\hline Part I: Intrapersonal competencies (IQ, EQ, AQ and SQ) & - Lecture \\
& - Warm up activities: "Brain twister questions" \\
Part II: Importance of intrapersonal competencies & - Self-reflection: "How are your intrapersonal competencies" \\
& - Lecture \\
Part III: Ways to promote intrapersonal competencies & - Group discussion: "Which Q?" \\
Part IV: Conclusion and sharing & - Lecture \\
\hline
\end{tabular}

different intrapersonal competencies (IQ, EQ, AQ and $\mathrm{SQ}) ; \mathrm{c})$ realize the relationships between different intrapersonal competencies (IQ, EQ, AQ and SQ) and effective service leadership; and d) suggest ways to promote different intrapersonal competencies (IQ, EQ, AQ and SQ).

In addition to direct lecturing, the teacher conducts class activities including group discussion and self-reflection. The lecture plan is presented below in Table 1.

This lecture begins with a warm-up activity of two brain twister questions. Students have to answer the questions as quickly as possible. They will be guided to evaluate whether these brain twisters can assess how intelligent one is. The activity is wrapped by introducing there are different kinds of intelligence (i.e. $\mathrm{IQ}, \mathrm{EQ}, \mathrm{AQ}, \mathrm{SQ}$ ), that constitute intrapersonal competencies. In the first part, four kinds of intelligence (IQ, EQ, AQ, SQ) are introduced to enable students to have a basic understanding. First, the teacher briefs on the concept of intelligence quotient (IQ) by presenting a simulated test item similar to those in the Raven's Progressive Matrices. Students will judge if IQ completely determines one's success. Briefly discussing this question, the teacher brings in the idea of emotional intelligence (EQ) that sometimes plays a heavier role in goal attainment. The teacher talks about the $\mathrm{EQ}$ model developed by Golemen [11]. The model describes five components: self-awareness, self-regulation, motivation, empathy, and social skills. Next comes AQ, a type of intelligence particularly for coping with adversity. Two knowledge points are highlighted. The first one focuses on the pursuit of human growth in adversity, and the second stresses changing challenge into opportunity. As students may not be familiar with $\mathrm{AQ}$ compared with IQ and EQ, this topic is illustrated by a video depicting the story of Nick Vujicic. Nick was born without limbs due to a rare disease. However, he demonstrated an extraordinarily high AQ. Through watching Nick's story, students are inspired and gain a better idea of AQ. Finally, the teacher asks a few questions to move to the topic of spiritual intelligence (SQ): "Do you believe in God or have other faith?”; "What is the ultimate meaning of life?"; and "Will you forgive someone if he/she offends or hurts you?" These questions link the abstract concept to daily life and prompt students to reflect on their lives. Further elaboration using real life examples is provided to show how to use spiritual resources to solve problems, which is the essential point of SQ.

By the end of this part, students are required to complete an online scale assessing intrapersonal competencies based on an existing question (source: http:// www.3smartcubes.com/pages/tests/intrapersonal_intelligence/intrapersonal_intelligence_questions.asp). This exercise (Worksheet 1$)^{1}$ serves two purposes. First, rating oneself in different aspects of intrapersonal competencies helps students to be more familiar with the concept. Second, the teacher will guide students to identify their weakness and strength in respective aspects of intrapersonal competencies.

The focus of the second part then switches to the importance of intrapersonal competencies. The teacher shows a model to demonstrate that knowing oneself and applying self-understanding to solve problems will enhance academic and career achievement. Then, the teacher presents research findings of desirable outcomes of intrapersonal competencies, e.g. psychological health, life satisfaction and effective leadership. In particular, he/she elaborates on the association between different kinds of intelligence (IQ, EQ, AQ, SQ) with service leadership: 1) IQ is important for effective service leadership because knowledge and skills are needed to optimize service quality; 2) EQ is important for effective leadership because a service leader needs to be aware of how his/her emotion may influence others and he/she has to behave accordingly; 3) AQ is significant because it is natural to have personal setbacks and problems while leading oneself and others; and 4) SQ is significant because through transcending oneself or knowing the meaning of life, one will be better prepared to provide high quality service in leadership.

1 Due to copyright, the worksheet 1 is not included in this paper. 
At the end of this part, students discuss in groups the application of IQ, EQ, AQ and SQ in real life situations. They receive three scenarios describing real life problems (see Worksheet 2) that ask them to decide which intrapersonal competency is the most important in the given situation. This activity helps students understand that the kind of intelligence required may vary across situations and solving one problem may require multiple intelligences.

The final part deals with ways to improve intrapersonal competencies. The teacher explains several possible approaches to improve intrapersonal competencies: self-awareness, self-regulation, determination and development of vision and values. Self-awareness highlights understanding oneself through self-reflection and listening to others' perspective. Self-regulation talks about controlling one's emotion and maintaining the alignment of behavior and values. Determination encourages building motivation to conquer difficulties and challenges. Development of vision and values leads to a quest for the meaning of life. The teacher will suggest specific tips to improve their intrapersonal competencies and asks students to propose and share their own ways of improving different kinds of intelligence among their groups. Each group gets a description of two specific competencies of a certain intelligence (see Worksheet 3). For example, one group obtains two specific competencies of $\mathrm{AQ}$ : "being able to change challenge into opportunity" and "maintaining hope and optimism in adverse situations". Students discuss with their group members how to improve respective abilities and post their tips on the white board in front of the class. This activity cultivates collaborative learning, which is one of features of this course. This part is wrapped up by highlighting that intrapersonal competencies are incremental and there are diverse approaches to improve intrapersonal competencies.

This lecture ends with a summary and discussion about related core beliefs. The lecture illustrates the component of competencies of leadership in the following formula:

$$
\mathrm{E}=\mathrm{MC}^{2} \text {, }
$$

where $\mathrm{E}$ stands for effective service leadership, $\mathrm{M}$ stands for moral character and $\mathrm{C}^{2}$ denotes competencies of leadership and a caring disposition. Improving intrapersonal competencies is part of self-leadership, which satisfies the needs of self. The relevant core beliefs include Core Belief 1 (leadership is a service aimed at ethically satisfying the needs of self, others, groups, community, systems and environments), Core Belief 3 (leadership effectiveness is dependent on possessing relevant situational task competencies plus being judged by superiors, peers and subordinates as possessing character and exhibiting care) and Core Belief 4 (service includes self-serving efforts aimed at ethically improving one's competences, abilities and willingness to help satisfy the needs of others). By the end of the class, a quotation by an American poet Susan Schutz is shared to wrap up the lecture on intrapersonal competencies: "This life is yours. Take the power to control your own life. No one else can do it for you. Take the power to make your life happy".

\section{Conclusion and reflection}

This lecture aims to enrich and expand students' understanding of what an effective service leader should be by introducing the concepts of IQ, EQ, AQ and SQ. In Hong Kong, tertiary education, research and teaching staff often reflect on what kind of education should be offered to university students. The previous preference of academic performance to psychosocial and spiritual aspects of youth development is problematic. In view of multiple existing youth problems, e.g. mental problems, heightened selfcenteredness, lack of citizenship and social responsibility, Shek and his associates $[60,61]$ advocate that nurturing holistic development (including physical, psychological, social and spiritual domains) among Hong Kong youth is an effective approach. Regarding this lecture, several points are noted in training intrapersonal competencies in Hong Kong young people.

First, IQ broadly involves adaptive problem-solving and critical thinking. Compared with a traditional education of logical reasoning, verbal ability and expertise knowledge and skills, the education of problem-solving and critical thinking has not received adequate attention.

Second, the notion of resilience is upheld in Chinese people as well. The extent of individual resilience is influenced by the beliefs one holds, especially cultural beliefs regarding adversity $[62,63]$. Two kinds of Chinese cultural belief concern adversity. Beliefs emphasizing the value of adversity and people's ability to conquer adversity, such as "ren ding sheng tian" (man is the master of his own fate), are associated with adaptive adjustment, e.g. greater well-being, less academic and behavioral problems. Beliefs highlighting fate control such as "hao chou ming sheng cheng" (whether life is good or bad depends on fate) are associated with maladaptive adjustment, e.g. lower well-being and more academic problems, both in the poor and non-poor adolescents, with a stronger impact on the first group [63]. These studies indicate a need for cultivating resilient cultural beliefs in Chinese youth. Unfortunately, resilience as a competency is less 
emphasized or even overlooked in formal education. Currently, children are likely raised in a greenhouse with lots of parental protection [64].

Despite the need for nurturing spirituality among youngsters [65], it would not be easy to implement in a materialistic environment. Preoccupation with material possession has become a growing concern in Chinese adolescents that could undermine spirituality [66]. Fostering spirituality may alleviate materialistic indulgency, e.g. conspicuous consumption [67]. Hence, it is worth presenting the concept of spiritual intelligence. In particular, students need to reconsider the meaning of life because "active reflection and experience are important processes in the development of spirituality" [68, p. 5].

Acknowledgments: The Service Leadership research project at The Hong Kong Polytechnic University is financially supported by the Victor and William Fung Foundation.

\section{Worksheet 2}

\section{Which Q?}

An effective service leader should possess a variety of attributes to progress in a constantly changing and challenging environment. In the different cases given below, please think about which Q (i.e. IQ, EQ, AQ or SQ) would be the most important to you in coping with the corresponding situation. Write down your answer and explain why.

\section{Scenario 1}

You are a final year student. You are going to attend an important qualifying examination. If you fail, you cannot graduate on time.

\section{Scenario 2}

You enter an internship program and also have to work as a sales person. One day you are late for work due to a traffic jam. Your sales manager criticizes your irresponsible and unreliable behavior without giving you a chance to explain.

\section{Scenario 3}

One day while shopping in a mall, you catch your best friend cheating on his/her partner.

\section{Worksheet 3}

\section{Group discussion: how to improve intrapersonal competencies}

Discuss how to improve the intrapersonal competencies listed below and suggest two strategies for each competency.

Write down your strategies and post them on the white board.

IQ: 1) Long attention span; 2) problem-solving skills; 3) extraordinary memory; 4) logical and analytical ability. EQ: 1) Able to recognize emotions of self and others; 2) able to read non-verbal messages of others; 3) balance feelings with reason, logic and reality; 4) not dominated by negative emotions.

AQ: 1) Able to withstand adversity and continue forward; 2) have control and influence in adversity; 3) able to change challenge into opportunity; 4) maintain hope and optimism in adverse situations.

SQ: 1) Able to forgive someone; 2) utilize spiritual resources (e.g. values or faith) to solve problems; 3 ) discover the meaning of life; 4) able to transcend beyond the self.

\section{References}

1. Gardner H. Intelligence reframed. New York, NY: Basic Books, 1999.

2. Gardner, H. The theory of multiple intelligences. Ann Dyslexia 1987;37:19-35.

3. Hogan R, Kaiser RB. What we know about leadership. Rev Gen Psychol 2005;9:169-80.

4. Day DV. Leadership development: a review in context. Leadership Quart 2001;11:581-613.

5. Neisser U, Boodoo G, Bouchard Jr TJ, Boykin AW, Brody N, Ceci SJ, et al. Intelligence: knowns and unknowns. Am Psychol 1996;51:77-101.

6. Sternberg RJ, Grigorenko E, Bundy DA. The predictive value of IQ. Merrill Palmer Quart 2001;47:1-41.

7. Simonton DK. Presidential IQ, openness, intellectual brilliance, and leadership: estimates and correlations for 42 US chief executives. Polit Psychol 2006;27:511-26.

8. Judge TA, Colbert AE, Ilies R. Intelligence and leadership: a quantitative review and test of theoretical propositions. J Appl Psychol 2004;89:542-52.

9. Jung DI. Transformational and transactional leadership and their effects on creativity in groups. Creativ Res 2001;13:185-95.

10. Locke EA. The essence of leadership. New York, NY: Lexington Books, 1991.

11. Goleman D. What makes a leader? Harv Bus Rev 1998;76:93-102.

12. Stoltz PG, Christensen CM. Adversity quotient: turning obstacles into opportunities. New York, NY: John Wiley, 1997. 
13. Zohar D, Marshall IN, Marshall I. SQ: connecting with our spiritual intelligence. New York, NY: Bloomsbury Publishing, 2000.

14. Salovey P, Mayer JD. Emotional intelligence. Imagin Cogn Pers 1990;9:185-211.

15. Mayer JD, Salovey P, Caruso DR. Emotional intelligence: theory, findings, and implications. Psychol Inq 2004;15:197-215.

16. Goleman D. Leadership that gets results. Harv Bus Rev 2000;78:78-93.

17. Goleman D. Emotional intelligence: why it can matter more than IQ. New York, NY: Random House Digital, Inc., 2006.

18. Goleman D. An El-based theory of performance. In: Cherniss C, Goleman D, editors. The emotionally intelligent workplace: how to select for, measure, and improve emotional intelligence in individuals, groups, and organizations. San Francisco, CA: Jossey-Bass, 2001:27-44.

19. Carmeli A. The relationship between emotional intelligence and work attitudes, behavior and outcomes: an examination among senior managers. J Manag Psychol 2003;18:788-813.

20. Rosete D, Ciarrochi J. Emotional intelligence and its relationship to workplace performance outcomes of leadership effectiveness. Leader Organ Dev J 2005;26:388-99.

21. Mayer JD, Salovey P, Caruso DR. Test manual for the Mayer, Salovey, Caruso Emotional Intelligence Test: research Version 1.1, 3rd ed. Toronto: MHS, 2002.

22. Kerr R, Garvin J, Heaton N, Boyle E. Emotional intelligence and leadership effectiveness. Leader Organ Dev J 2006;27:265-79.

23. Walter F, Cole MS, der Vegt GS, Rubin RS, Bommer WH. Emotion recognition and emergent leadership: unraveling mediating mechanisms and boundary conditions. Leadership Quart 2012;23:977-91.

24. Luthar SS, Cicchetti D, Becker B. The construct of resilience: a critical evaluation and guidelines for future work. Child Dev 2000;71:543-62.

25. Margolis JD, Stoltz PG. How to bounce back from adversity. Harv Bus Rev 2010;88:86-92.

26. Boniwell I. Positive psychology in a nutshell: the science of happiness. Maidenhead: McGraw-Hill International, 2012.

27. Luthans $F$. The need for and meaning of positive organizational behavior. J Organ Behav 2002;23:695-706.

28. Garmezy N. Resilience in children's adaptation to negative life events and stressed environments. Pediatrics 1991;20:459-66.

29. Carle AC, Chassin L. Resilience in a community sample of children of alcoholics: its prevalence and relation to internalizing symptomatology and positive affect. J Appl Dev Psychol 2004;25:577-95.

30. Masten A, Coatsworth JD. The development of competence in favorable and unfavorable environments: lessons from research on successful children. Am Psychol 1998;53:205-20.

31. Cicchetti D, Rogosch FA, Lynch M, Holt K. Resilience in maltreated children: processes leading to adaptive outcomes. Dev Psychopathol 1993;5:629-47.

32. Collishaw S, Pickles A, Messer J, Rutter M, Shearer C, Maughan B. Resilience to adult psychopathology following childhood maltreatment: evidence from a community sample. Child Abuse Negl 2007;3:211-29.

33. Klasen F, Oettingen G, Daniels J, Post M, Hoyer C, Adam H. Posttraumatic resilience in former Ugandan child soldiers. Child Dev 2010;81:1096-113.

34. Olsson CA, Bond L, Burns JM, Vella-Brodrick DA, Sawyer SM. Adolescent resilience: a concept analysis. J Adolesc 2003;26:1-11.
35. King GA, Rothstein MG. Resilience and leadership: the selfmanagement of failure. In: Rothstein MG, Burke RJ, editors. Self-management and leadership development. Cheltenham: Edward Elgar, 2010:361-94.

36. Mangurian GE. Realizing what you're made of. Harvard Bus Rev 2007;85:125-30.

37. Shambaugh R. The secrets of resilient leaders. Leader Leader 2010;58:39-44.

38. Stoltz PG. Building resilience for uncertain times. Leader Leader 2004;31:16-20.

39. Emmons RA. Spirituality and intelligence: problems and prospects. Int J Psychol Relig 2000;10:57-64.

40. Emmons RA. Is spirituality an intelligence? Int J Psychol Relig 2000;10:27-34.

41. Zohar D. Spiritually intelligent leadership. Leader Leader 2005;38:45-51.

42. Shek DT. The spirituality of the Chinese people: a critical review. In: Bond MH, editor. Oxford handbook of Chinese psychology. New York, NY: Oxford University Press, 2010:343-66.

43. Chiu C, Hong Y, Dweck CS. Toward an integrative model of personality and intelligence: a general framework and some preliminary steps. In: Sternberg RJ, Ruzgis P, editors. Personality and intelligence. New York, NY: Cambridge University Press, 1994:104-34.

44. Walters JM, Gardner H. The theory of multiple intelligences: some issues and answers. In: Sternberg RJ, Wagner RK, editors. Practical intelligence. New York, NY: Cambridge University Press, 1986:163-82.

45. Ryan RM, Deci EL. On happiness and human potentials: a review of research on hedonic and eudaimonic well-being. Annu Rev Psychol 2001;52:141-66.

46. Frankl VE. Man's search for meaning: an introduction to logotherapy. New York, NY: Washington Square Press, 1963.

47. Zika S, Chamberlain K. On the relation between meaning in life and psychological well-being. Br J Psychol 1992;83:133-45.

48. Shek DT. Meaning in life and psychological well-being in Chinese college students. Int Forum Logotherapy 1993;16:35-42.

49. Shek DT. Meaning in life and adjustment amongst early adolescents in Hong Kong. Int Forum Logotherapy 1999;22:36-43.

50. Ho MY, Cheung FM, Cheung SF. The role of meaning in life and optimism in promoting well-being. Pers Indiv Differ 2010;48:658-63.

51. Laabs JJ. Balancing spirituality and work. Pers J 1995;74:60-77.

52. Fry LW. Toward a theory of spiritual leadership. Leadership Quart 2003;14:693-727.

53. Conger JA, Kanungo RN. Charismatic leadership in organizations: perceived behavioral attributes and their measurement. J Organ Behav Manag 1994;15:439-52.

54. Avolio B, Waldman D, Yammarino F. Leading in the 1990's: the four I's of transformational leadership. J Eur Ind Train 1991;15:9-16.

55. Russell RF, Stone AG. A review of servant leadership attributes: developing a practical model. Leader Organ Dev J 2002;23:145-57.

56. Bhindi N, Duignan P. Leadership for a new century: authenticity, intentionality, spirituality, and sensibility. Educ Manag Admin 1997;25:117-32.

57. Karakas F. Spirituality and performance in organizations: a literature review. J Bus Ethics 2010;94:89-106.

58. Hong Kong Institute of Service Leadership and Management Limited. Essential Knowledge Strands (eKs) [Internet]. Hong Kong: Hong Kong Institute of Service Leadership and 
Management Limited; 2013. Avaialble at: http://server.gopublic. com.hk:3993/slam/index.php? $r=$ article\&catid=3\&aid $=42$. Accessed: 20 Nov 2013.

59. Simon NJ. Cl soft skill competencies. Competitive Intelligence Magazine 1999;2:48-9.

60. Shek DT. Nurturing holistic development of university students in Hong Kong: where are we and where should we go? ScientificWorldJournal 2010;10:563-75.

61. Shek DT, Wong KK. Do adolescent developmental issues disappear overnight? Reflections about holistic development in university students. ScientificWorldJournal 2011;11: 353-61.

62. Leung JT, Shek DT. Psychometric properties of the Chinese cultural beliefs about adversity scale. Res Social Work Pract 2013;23:326-35.

63. Shek DT. Chinese cultural beliefs about adversity: its relationship to psychological well-being, school adjustment and problem behavior in Hong Kong adolescents with and without economic disadvantage. Childhood 2004;11:63-80.
64. Shek DT, Lin L. Qualitative evaluation of the project P.A.T.H.S.: narrative findings based on focus groups with participating students. In: Shek DT, Sun RC, editors. Development and evaluation of positive adolescent training through holistic social programs (P.A.T.H.S.). Berlin: Springer, 2013:165-77.

65. Shek DT. Life meaning and purpose in life among Chinese adolescents: what can we learn from Chinese studies in Hong Kong? In: Wong PT, editor. The human quest for meaning: theories, research, and applications, 2nd ed. New York, NY: Routledge, 2012:335-56.

66. Shek DT, Ma CM, Lin L. The Chinese Adolescent Materialism Scale: psychometric properties and normative profiles. Int J Disabil Hum Dev 2014;13:285-95.

67. Stillman TF, Fincham FD, Vohs KD, Lambert NM, Phillips CA. The material and immaterial in conflict: spirituality reduces conspicuous consumption. J Econ Psychol 2012;33:1-7.

68. Shek DT. Spirituality as a positive youth development construct: a conceptual review. ScientificWorldJournal 2012;2012:458953. 